\title{
Un siglo de expansión y divergencia. Inversión en maquinaria en una economía periférica Chile $1830-1938$
}

Cristián Ducoing Ruiz*

INVESTIGADOR POSTDOCTORAL, UNIVERSIDAD DE UMEÅ

\section{RESUMEN}

El desarrollo económico de Chile representa un interesante caso de divergencia y convergencia con los países desarrollados. A finales del siglo XIX su PIB per cápita era comparable con el de la periferia Europea y superaba con creces lo de actuales países desarrollados del sudoeste asiático. No obstante, después de la Primera Guerra Mundial y particularmente en los años posteriores a la Gran Depresión, Chile comenzó a mostrar claro signos de agotamiento de su modelo de crecimiento. El presente artículo, utilizando el trabajo cuantitativo y de elaboración de series de capital físico en maquinaria de recientes trabajos (tesis doctorales, artículos y capítulos de libros) más fuentes primarias, analiza la influencia de la formación de capital físico en maquinaria y su relación con la divergencia de Chile con el grupo de países avanzados. Además, se presenta un análisis sectorial de la inversión en maquinaria según los principales sectores productivos.

Palabras clave: Maquinaria y equipamiento, Chile, Divergencia

\section{Abstract}

The economic development of Chile represents an interesting case of divergence and convergence with developed countries. In the late nineteenth century, its GDP per capita was comparable with some countries of the European periphery and far exceeded the current developed countries of South East Asia. However, after the First World War and particularly in the years following the Great Depression, Chile began to show clear signs of exhaustion of its growth model. This article, using quantitative series of physical capital in machinery of recent works (doctoral theses, articles and book chapters) plus primary sources, the influence of physical capital formation in machinery is analyzed and their relationship with the divergence of Chile with the group of advanced countries. Additionally, this article presents a sectoral analysis of investment in machinery for the main productive sectors.

Keywords: Machinery \& Equipment, Chile, Divergence

*cristian.ducoing@umu.se 


\section{INTRODUCCIÓN}

iversos estudios han llegado a la conclusión que la maquinaria es un buen proxy de la modernización de la economía (B. DeLong \& Summers, 1991; J. B. DeLong, 1992). Por ejemplo, la razón fundamental del proceso industrializador de Inglaterra está determinado por la relación favorable de altos salarios y bajos precios de la energía, (Allen, 2009) que hacen rentable la inversión en R\&D y la utilización de bienes de capital (Maquinaria) con el fin de aumentar la producción y la productividad del trabajo. Nada muy distinto a los incentivos que existieron en Chile para que un proceso similar se experimentara. No es de extrañarse, que con salarios bajos y precios de la energía medio - altos, los incentivos para un proceso de mecanización estuvieran ausentes al promediar 1830. No obstante, esto no significó la ausencia de adelantos tecnológicos, como fue la utilización del horno de reverbero en la minería del cobre, que permitió aumentar exponencialmente las exportaciones del mineral en cuestión en la primera mitad del siglo XIX (Valenzuela, 1995).

El objetivo de este artículo es explicar el desempeño de la economía chilena, desde la perspectiva de la inversión en maquinaria para el periodo 1830 - 1938. Tomando en cuenta lo avanzado del debate sobre la importancia de la maquinaria en el proceso de crecimiento económico, ya sea desde una perspectiva de acumulación y rendimientos decrecientes como fue explicitado por Solow $(1956)^{1}$; o de la perspectiva más moderna de crecimiento con rendimientos crecientes y contabilidad del crecimiento tecnológico por medio de la inversión en maquinaria expresados y fundamentados por Romer $(1986)^{2}$ y Greenwood, Hercowitz, \& Krusell $(1997)^{3}$, la hipótesis central testeada en este trabajo es la existencia (o no) de un crecimiento sostenido de la inversión en maquinaria; por lo tanto, el retraso relativo de Chile al final del periodo estudiado, y probablemente, hasta la actualidad, podría estar relacionado con una ralentización de la inversión en maquinaria en el periodo comprendido entre la Primera Guerra Mundial y la Gran Depresión.

Dependiendo del indicador económico elegido, Chile puede entrar en el grupo de los países periféricos que desaprovecharon la primera 
gran globalización (1870 - 1913) o los que avanzaron decididamente hacia el progreso económico, pero no pudieron continuar el tranco producto de los vaivenes de la economía mundial, aspectos institucionales internos o políticas económicas equivocadas. Si el indicador elegido es el PIB per cápita, esta comparación tendría que ser realizada con sus pares latinoamericanos y la periferia europea, puesto que la común medición con los Estados Unidos distorsiona las comparaciones ${ }^{4}$.

Pese a comenzar el periodo independiente con un nivel similar al de México y Brasil, Chile al finalizar el siglo XIX contaba con PIB per cápita comparable al de Argentina y levemente superior al de Suecia. Brasil había quedado muy rezagado en términos de PIB, mientras México comenzaba a recuperar el terreno perdido durante el difícil periodo post independencia. Al finalizar el periodo estudiado, Chile se mantenía por sobre Brasil y México, pero se había distanciado de Argentina y Suecia le había superado largamente (pese a estar al mismo nivel en 1900). ¿Se puede explicar esta divergencia por medio de la inversión en maquinaria? $\mathrm{O}$ al menos, ¿podemos establecer una cronología que permita conocer las etapas de convergencia y divergencia de la economía chilena?

No solamente el monto total de la inversión en maquinaria y equipos es la preocupación de este artículo, también lo es la distribución sectorial de la misma. Al respecto, se realiza en este artículo un análisis de la destinación final de las inversiones, para considerar que sectores fueron los fundamentales en el crecimiento de la economía chilena en el plazo estudiado y cómo a través de la destinación sectorial podemos estimar la existencia de un cambio estructural.

Tabla 1: PIB per cápita de países latinoamericanos, americanos y europeos seleccionados en 1830, 1870, 1900 y 1938

\begin{tabular}{|l|r|r|r|r|}
\hline Pais & $\mathbf{1 8 2 0}$ & $\mathbf{1 8 7 0}$ & $\mathbf{1 9 0 0}$ & $\mathbf{1 9 3 8}$ \\
\hline Argentina & 998 & 1468 & 2875 & 4072 \\
\hline Brasil & 683 & 713 & 678 & 1276 \\
\hline Chile & 694 & 1290 & 2194 & 3161 \\
\hline USA & 1547,1 & 2444,6 & 4014,9 & 5998,7 \\
\hline España & & 1207,1 & 1786,3 & 1790,2 \\
\hline Suecia & 921,3 & 1345,1 & 2083,0 & 4900,9 \\
\hline México & 627 & 651 & 1319 & 1858 \\
\hline
\end{tabular}

Fuente: Actualización del proyecto Maddison (Bolt \& van Zanden, 2014) 
COMPORTAMIENTO Y PRINCIPALES CARACTERÍSTICAS DE LA FBCM en Chile durante el periodo i 830 - I 938

Para entender la relación conceptual expuesta sobre la influencia de la inversión en maquinaria sobre el crecimiento económico, se ha construido una serie de formación bruta de capital fijo en maquinaria (desde ahora, FBCM) para el periodo 1830 - 1938.

La construcción de la serie en maquinaria en cuestión se explica ampliamente en anteriores investigaciones (Ducoing \& Tafunell 2013; Ducoing 2012). En forma resumida, la serie de formación bruta de capital fijo en maquinaria se elaboró en su inmensa mayoría en base a las estadísticas comerciales chilenas, complementadas con las estadísticas comerciales del llamado G3, compuesto por Alemania, Estados Unidos y el Reino Unido. Estos tres países eran los mayores productores de maquinaria hasta principios del siglo XX y fueron los mayores proveedores de equipos para los países latinoamericanos hasta que estos comenzaron a producir su propia maquinaria (Tafunell, 2009). En el caso de Chile, como bien han demostrado Badia-Miró \& Ducoing (2013) y Ducoing, (2012), la producción de maquinaria nacional podría ser considerada "testimonial" hasta bien entrado el siglo XX. Sólo con la Segunda Guerra Mundial y las políticas de industrialización promovidas por el Estado, la producción de maquinaria y equipos supera el 10\% del total (Ducoing, 2012, p. Apéndices).

La serie de FBCM proporciona una cronología certera sobre los ciclos de crecimiento y contracción de la economía chilena, así también permite entender las razones de la divergencia con los países de avanzada.

ANÁLISIS ENDÓgENOS Y EXÓGENOS DE LA SERIE TEMPORAL. UNA NUEVA CRONOLOGÍA PARA LA HISTORIA ECONÓMICA CHILENA

Constantemente, se habla de una historia económica de Chile hasta 1879 y una nueva forma para analizarla entre 1880 - 1930 (Cariola $\&$ Sunkel, 1982) 5 . Estos periodos han sido seleccionados tomando en cuenta los análisis historiográficos clásicos de la historia económica chilena, por tanto, no son los adecuados para realizar un estudio exhaustivo y/o novedoso del comportamiento agregado de la varia- 
ble FBCM en el largo plazo, y menos para estimar las relaciones implícitas de la inversión en maquinaria y el crecimiento económico.

En términos historiográficos tradicionales, se habla de ciclos de expansión y contracción en el periodo 1830 - 1938 (Mamalakis, 1976) ${ }^{6}$. En cuanto a los ciclos de expansión, determinados por tasas de crecimiento superiores al promedio total del periodo en cuestión, se consideran como los periodos de bonanza, los años $1850 \mathrm{al}$ $1857^{7}, 1865$ - 1873, $1880-1891,1902-1912,1923-1929$ y 1935 - 1938. Con respecto a los ciclos de depresión o contracción ${ }^{8}$, estos se presentaron con mayor intensidad en los años 1858 - 1862, 1876 - 1879, 1891 - 1894, 1913 - 1916, 1920 - 1922 y 1929 - 1932. Mantener esta percepción de los ańos por medio de los ciclos comúnmente tratados por la historiografía económica chilena, podría resultar contraproducente para lograr tener una visión actualizada del cambio en la economía chilena por medio de la FBCM. Por esta razón se recurre al test de quiebre estructural ${ }^{9}$, para estimar nuevos periodos o ciclos por parte de la economía chilena. El test más indicado para determinar posibles cambios de tendencia significativos es el de quiebre estructural; no solo por medio de las tasas de crecimiento y decrecimiento del PIB. También, hemos considerado las tasas de la FBCM, con el fin de conocer si las relaciones entre ambas variables sufren cambios, o las interdependencias son más o menos causales de lo que se pensaba anteriormente.

Se aplicó a la serie agregada de maquinaria y equipos 1830 y 1938 , el test de Chow, (1960), con el fin de encontrar quiebres estructurales en las tasas de crecimiento. La cantidad de quiebres se define a priori, y por lo general se elige el número de quiebres de acuerdo a la cantidad de años en cuestión. La intención es conocer cuáles son los dos principales periodos económicos de la historia económica chilena.

La definición básica del test parte de la premisa que una serie de tiempo puede sufrir cambios estructurales en periodos determinados que significan cambios permanentes a posteriori. En el caso que estamos analizando de la FBCM, deberemos decidir si existen razones para pensar en un gran quiebre estructural o al menos dos quiebres estructurales menores en el plazo de cien años. 
Gráfico 1: La FBCM de Chile 1830 - 1938 y con los quiebres estructurales estimados.

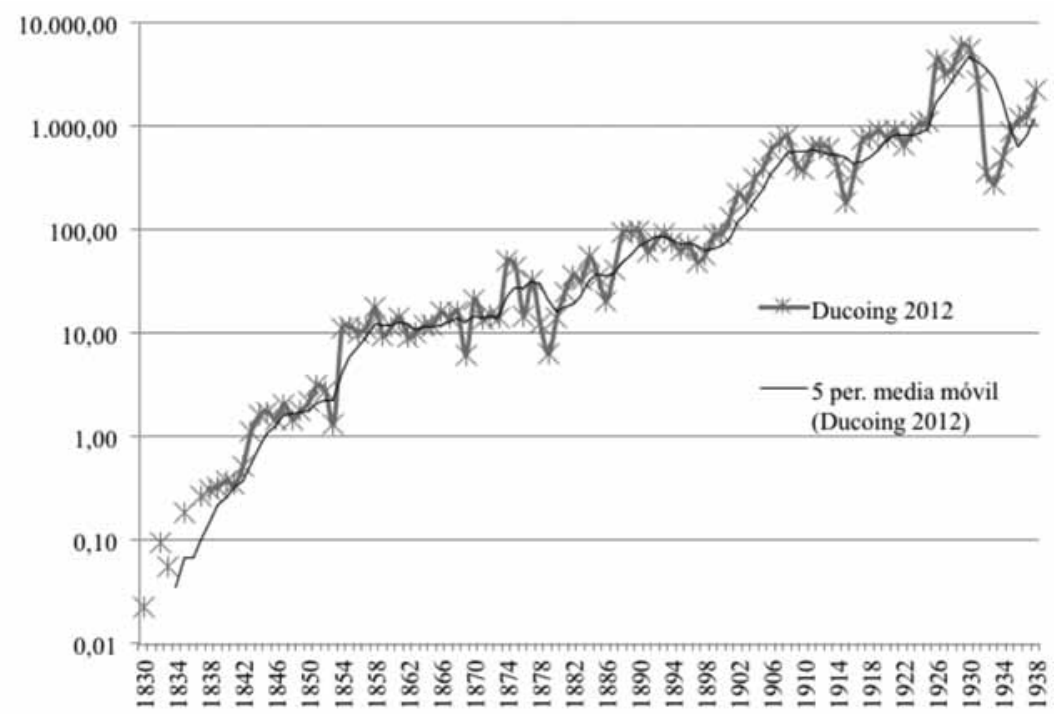

Fuente: (Ducoing, 2012)

Como se observa en el gráfico №1, se pueden estimar dos quiebres estructurales en la economía chilena tomando como variable dependiente la FBCM: 1853 año donde comienza un salto importante de la tasa de participación de la FBCM en el PIB y el índice de la FBCM pasa de 1,37 a 11,52 en 1854; el otro quiebre estaría radicado en los ańos 1897 - 1899, donde el índice pasa de ser de 50,49 en 1897 a 89,76 en 1899. Estos años no impide ver otros importantes cambios o estancamientos en el comportamiento de la FBCM, como supone el observar la década de 1870; antes de la Guerra del Pacífico, se redujo el envío de maquinaria es fuertes cantidades; en 1870 las importaciones de maquinaria alcanzaban a 936.705 pesos de $18 \mathrm{~d}$ y en 1879 esta cifra se había reducido a $859.025^{10}$. No obstante, mientras que en 1870 la FBCM representaba el 3,3\% de las importaciones totales, en 1879 este porcentaje había aumentado al 3.9\%. Por lo tanto, el tan mencionado quiebre producido por la Guerra del Pacífico, en términos de esfuerzo 
inversor no es tal, siendo los cambios de nivel producidos en los años 1853 - 1854 y 1897 - 1899 mucho más importantes y significativos. Este es un ejemplo claro que ciertas concepciones de la historiografía económica tradicional de Chile son parciales y no distinguen de procesos de modernización y quiebres estructurales, de coyunturas específicas que no representan un cambio fundamental en la economía del país. Regularmente se ha sobreestimado el significado de la Guerra del Pacífico en la estructura económica de Chile. No obstante, los efectos permanentes sobre la estructura económica chilena son identificables a principios del siglo XX, periodo en el cual la participación de la FBCM en las importaciones y en el PIB aumenta significativamente y las tasas de crecimiento son constantes, como es posible observar en el gráfico No1. Más significativo es, en términos de estancamiento, el efecto negativo que tuvo sobre el proceso de modernización chileno el estallido de la Primera Guerra Mundial. Sobre la base de que la inmensa mayoría de la FBCM era de origen extranjero, el cierre de los mercados internacionales significó no solo el comienzo del fin del ciclo salitrero, también la perdida de los mercados abastecedores de las maquinarias que llevaban a cabo el salto modernizador e industrializador que aparentaba tener Chile hasta 1913. El esquema de los quiebres y de grandes cambios estructurales que deberían advertirse en la serie de FBCM y en la serie de PIB, no es el único análisis importante. Los dos grandes quiebres establecidos, a mediados de la década de 1850 y a finales del siglo XX, son importantes para establecer visiones actualizadas sobre la historia económica chilena y su maquinización, pero debe estar complementada por otro tipo de análisis estadísticos, como es el estudio sobre la volatilidad de la inversión. Para realizar este análisis, será necesario establecer otros periodos más cortos que los dos grandes quiebres explicitados.

\section{VOLATILIDAD DE LA INVERSIÓN EN MAQUINARIA Y EQUIPOS}

La volatilidad de la formación bruta de capital fijo es considerada de 3 a 1 con respecto al producto en el caso de Chile, tomando cifras de la segunda mitad del siglo XX (Magendzo, 2004). Puede estar bajo o 
sobre esta cifra tentativa, dependiendo mucho del ciclo económico en que se encuentre el análisis, pero por lo general, es posible afirmar que las tasas de crecimiento y la consecuente volatilidad de las diferencias entre intervalos y periodos es mayor en la inversión (en cualquiera de sus formas, infraestructura o bienes de capital) que en el producto total. Esta situación se repite cuando analizamos las tasas de crecimiento de la FBCM y las comparamos con los resultados en los mismos periodos con el PIB.

Tabla 2: Tasa de crecimiento en periodos seleccionados. PIB y FBCM ${ }^{11}$

\begin{tabular}{|c|c|c|c|}
\hline Periodos & PIB & FBCM & Ratio FBCM/PIB \\
\hline $1830-1938$ & 2,96 & 6,75 & 2,3 \\
\hline $1844-1873$ & 3,9 & 13,23 & 3,4 \\
\hline $1874-1904$ & 2,85 & 3,49 & 1,2 \\
\hline $1905-1919$ & 1,38 & 3,56 & 2,6 \\
\hline $1920-1938$ & 2,26 & $-0,3$ & $-0,1$ \\
\hline $1929-1932$ & $-8,89$ & $-53,72$ & \\
\hline
\end{tabular}

Fuente: PIB, (Díaz, Lüders, \& Wagner, 2010) , FBCM, (Ducoing, 2012)

Los resultados de esta comparación resumida en la tabla No 2 son clarificadores. Las tasas de crecimiento y decrecimiento de la FBCM triplican, cuadriplican e incluso quintuplican (en los años 1929 - 1932 ${ }^{12}$ las tasas de crecimiento y decrecimiento del PIB, para iguales periodos. Si analizamos un periodo de crisis como 1929 - 1932, entendemos que la situación de decrecimiento se condice con un estancamiento casi absoluto con las inversiones en nuevas máquinas ${ }^{13}$.

Pese a la claridad que entregan estas cifras, es pertinente hacer otros análisis para conocer la volatilidad más allá de la comparación con el PIB. Una de estas formas es conocer la desviación estándar y los coeficientes de variación de la serie. Se han dividido en este análisis tres series: La serie de FBCM agregada 1830 - 1938, la serie de inversión en maquinaria 1830 - 1938 y la serie de transporte, 1844 - 1938. Lamentablemente no se conocen los datos desagregados entre transporte y maquinaria para el periodo $1830-1843$. 
Tabla 3: Descripción estadística de las series de maquinaria y PIB $(1830$ - 1938)

\begin{tabular}{|l|c|l|c|}
\hline & FBCM & & PIB \\
\hline Promedio & 291.1600 & Promedio & 82.11927 \\
\hline Mediana & 57.50000 & Mediana & 68.00000 \\
\hline Maximum & 2222.000 & Maximum & 237.0000 \\
\hline Minimum & 0.4 & Minimum & 10.00000 \\
\hline Des. Estandar & 450.2112 & Des. Estandar & 63.83250 \\
\hline Skewness & 2.076691 & Skewness & 0.643794 \\
\hline Kurtosis & 7.585218 & Kurtosis & 2.246217 \\
\hline & & & \\
\hline Jarque-Bera & 159.4783 & Jarque-Bera & 10.11008 \\
\hline Probabilidad & 0.000000 & Probabilidad & 0.006377 \\
\hline & & & \\
\hline Sum & 29116.00 & Sum & 8951.000 \\
\hline Sum Sq. Dev. & 20066325 & Sum Sq. Dev. & 440055.4 \\
\hline & & & \\
\hline Observaciones & 109 & Observaciones & 109 \\
\hline
\end{tabular}

Fuente: Maquinaria, apéndice No 1 en (Ducoing, 2012) y PIB (Díaz et al., 2010).

Las diferencias con respecto a la desviación estándar confirman la existencia de una volatilidad mucho mayor de la FBCM en comparación a la serie de PIB. Mientras que la desviación standard de la maquinaria es de 450,2, la desviación estándar del PIB es de 63,8.

La comparación de la desviación estándar de la maquinaria con la desviación estándar del PIB muestra que la volatilidad de la maquinaria es elevada. Queda por comprobar si esta volatilidad de la inversión en maquinaria es una característica propia de la economía chilena en la segunda mitad del siglo XIX y la primera parte del siglo XX o es una característica compartida con otras economías latinoamericanas y europeas (de nivel de desarrollo económico similar a Chile en el XIX). Para llevar a cabo esta medición, utilizamos los datos de economías de niveles de ingreso similares a Chile en 1860, como Argentina, Suecia y Espańa y comparamos sus niveles de variación en el plazo de tiempo en el cual disponemos de los datos suficientes para realizar una estimación de largo plazo. 
Tabla 4: Sumario estadístico de las series de FBCM de Argentina, Chile, España y Suecia. 1860 - 1938

\begin{tabular}{|l|c|c|c|c|}
\hline & Chile & España & Suecia & Argentina \\
\hline Promedio & 367,29 & 118,48 & 124,2658 & 245,3797 \\
\hline Mediana & 104 & 33 & 55 & 99 \\
\hline Maximum & 2222 & 653 & 575 & 1261 \\
\hline Minimum & 7 & 3 & 9 & 1 \\
\hline Des. Estandar & 478,85 & 140,96 & 148,13 & 304,33 \\
\hline Skewness & 1,77 & 1,57 & 1,502391 & 1,472309 \\
\hline Kurtosis & 6,22 & 5,54 & 4,082989 & 4,577395 \\
\hline & & & & \\
\hline Jarque-Bera & 75,31 & 53,45 & 33,58019 & 36,73155 \\
\hline Probabilidad & 0 & 0 & 0 & 0 \\
\hline & & & & \\
\hline Sum & 29016 & 9360 & 9817 & 19385 \\
\hline Sum Sq. Dev. & 17885332 & 1549840 & 1711569 & 7224548 \\
\hline & & & & 79 \\
\hline Observaciones & 79 & 79 & 79 & \\
\hline
\end{tabular}

Fuentes: Chile, (Ducoing, 2012); España (de la Escosura, 2003); Suecia (Lobell, Schön, \& Krantz, 2008) y Argentina, (Tafunell, 2013)

¿Puede haber afectado al rendimiento de la economía chilena el nivel de volatilidad de la inversión en maquinaria? Tal como lo indican los datos de desviación estándar y coeficientes de variación, la inversión en maquinaria chilena sufrió de variaciones enormes en plazos muy cortos de tiempo, incluso comparando estos datos con economías de similar nivel de desarrollo. El trabajo sobre el desarrollo económico latinoamericano realizado por Bértola \& Ocampo (2013) apunta a la volatilidad como una de las causas del retraso relativo del continente con respecto a los países desarrollados. Es una arriesgada suposición que la extremada volatilidad de la variable FBCM sea la causa del languidecimiento del crecimiento económico chileno en el periodo 1913 - 1938, pero es una posibilidad no descartable de antemano, puesto que la volatilidad de la FBCM está relacionada con menores tasas de crecimiento del 
stock de capital en el largo y mediano plazo; este hecho se comprueba cuando comparamos la tasa de crecimiento del stock de capital en maquinaria en los periodos más volátiles con respecto a los periodos de mayor estabilidad en las tasas de crecimiento y de participación en el producto.

TASAS DE PARTICIPACIÓN DE LA FBCM EN LAS IMPORTACIONES Y EN EL PRODUCTO

Una forma de estimar la importancia que tuvo la maquinaria en la estructura económica de un país, es medir el peso de la FBCM en el producto, y en el caso de Chile, en las importaciones, por las razones expuestas en trabajos anteriores (Ducoing \& Tafunell, 2013; Ducoing, 2012). La tasa de participación de la maquinaria en el producto se define como el ratio entre el valor de la maquinaria invertida en un año y el producto del mismo año en cuestión $\left(\frac{I m q_{t}}{P I B_{t}}\right)$. Este tipo de mediciones son comunes en los análisis sobre los efectos de la maquinaria en el crecimiento económico, y han sido el principal argumento que han utilizado J. B. DeLong \& Summers (1991, 1992) en sus artículos, para estimar las diferencias en las tasas de crecimiento económico.

Gráfico 2: Tasa de participación de la maquinaria en el producto y las importaciones. $1844-1938^{14}$

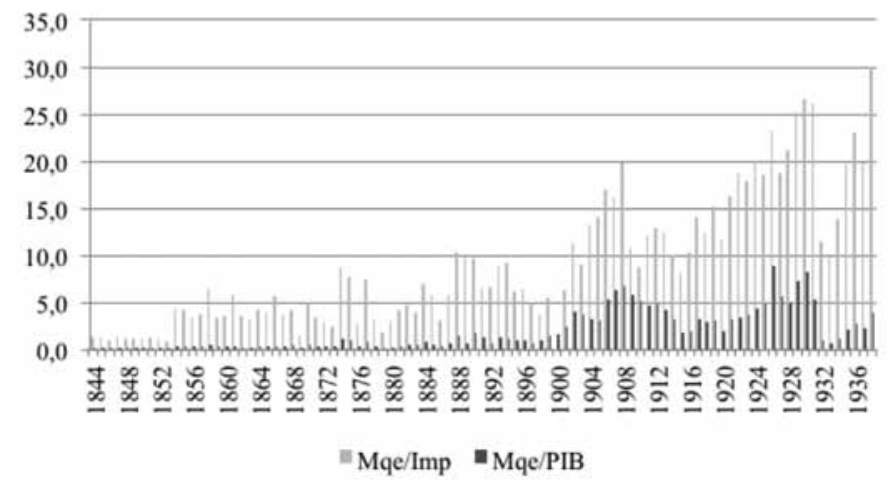

Fuente: (Ducoing, 2012) Apéndice No6. 
Como se observa en el Gráfico No 2, la tasa de participación de la FBCM en el producto y las importaciones fue creciendo paulatinamente, pero siempre con una extrema volatilidad. Durante 1860 - 1938, los periodos donde la participación de la FBCM sobre el PIB es mayor es la década de $1902-1912$ y donde alcanzó cifras de $6,81 \%$ en el producto y hasta $20 \%$ del total de las importaciones. El otro periodo destacable en tasas de participación es el periodo de la década de 1920, donde se alcanzaron cifras de participación del $8,86 \%$ del PIB. El periodo de alta formación de capital en maquinaria no se mantendrá en el tiempo y con la llegada de la primera Guerra Mundial, las tasas volverán a los niveles exhibidos en los ańos precedentes al Siglo XX. Esto es un antecedente a tener en cuenta cuando se analiza la industrialización pre ISI. Si comparamos con las tasas de países como Suecia, donde la tasa de participación de la maquinaria en el producto fue aumentando lenta, pero continuamente, desde un $2 \%$ en la década de 1870 a un $6 \%$ en la década de 1930 (Lobell et al., 2008). En el caso de Chile, está situación es diametralmente distinta; en la década de 1870 la tasa de participación de la FBCM oscilaba entre un $0,9 \%$ y el 3,1\% del PIB y esta relación varió, pero no de la forma excepcional que había ocurrido en el caso sueco; en Chile, la FBCM sobre el PIB en la década de 1930 oscilaba entre un $0,8 \%$ y $2,75 \%$ del PIB. Supuestamente, ambos países estaban llevando a cabo un proceso de Industrialización en el periodo 1870 - 1930, y el nivel inicial de PIB per cápita sueco en este periodo era similar al chileno. Aún más aclaratorio resulta comparar el nivel de la tasa de participación de la FBCM para la industria en el producto, en el periodo 1865 - 1912, con el periodo posterior. Las nuevas estimaciones de PIB industrial para el periodo $1880-1930$ confirman la debilidad de la industrialización chilena durante el ciclo del salitre (Badia-Miró \& Ducoing, 2013, 2015).

Finalmente, la tabla No 5 sintetiza los principales indicadores de crecimiento y de participación de la FBCM sobre las importaciones y el PIB en los periodos seleccionados. Algunos periodos, como el de $1830-1873$, aparecen con tasas de crecimiento muy altas, pero 
eso está determinado por las bajas tasas de participación iniciales sobre el PIB y las importaciones. En la medida que el crecimiento fue asentándose, las tasas se ralentizaron, hasta estancarse en un 4\% en el siglo XX. Este cambio, característico de las economías que se industrializan (un aumento de la tasa de participación de la FBCM en el PIB, pero a menores tasas de crecimiento mientras aumenta la participación), en el caso chileno fue más acentuado y la década posterior a la crisis de 1929 fue sumamente decepcionante en tasas de participación y crecimiento, perdiendo mucho peso la maquinaria en el producto (no así en las importaciones) ${ }^{15}$.

Tabla 5: Análisis de indicadores de PIB y relación de la FBCM con las Importaciones y el PIB

\begin{tabular}{|c|c|c|c|c|}
\hline Años & $\begin{array}{c}\text { Crecimiento PIB } \\
(1880=100)\end{array}$ & FBCM/PIB & $\begin{array}{c}\text { FBCM/ } \\
\text { Importaciones }\end{array}$ & $\begin{array}{c}\text { Tasa de } \\
\text { crecimiento } \\
\text { de la FBCM }\end{array}$ \\
\hline $1830-1938$ & 2,78 & 2,04 & 6,24 & 8,57 \\
\hline $1830-1873$ & 3,63 & 0,29 & 3,46 & 9,17 \\
\hline $1874-1902$ & 3,34 & 1,28 & 8,1 & 5,38 \\
\hline $1903-1938$ & 2,47 & 3,48 & 11,3 & 3,96 \\
\hline
\end{tabular}

Fuentes: Columna Crecimiento PIB:(Díaz et al., 2010). Columna FBCM/PIB, (Ducoing, 2012) y (Díaz et al., 2010) Columna FBCM/ Importaciones, Apéndice No 1, Ibañez (1928) y Díaz et. al (2007); Columna Tasa de Crecimiento de la FBCM, (Ducoing \& Tafunell, 2013; Ducoing, 2012) Apéndice No 2.

\section{TASAS DE LA FBCM PER CÁPITA}

El valor absoluto de la FBCM reviste menos interés si no está relacionado y puesto en contexto con otras variables. Una forma simple de estimar el esfuerzo inversor de un país y comprender su estructura económica es realizar un análisis de las tasas per cápita de inversión. No obstante, hay que dar a entender que existe a lo largo de los ańos un cambio demográfico que afecta la influencia que puede tener la inversión sobre la fuerza laboral, puesto en la medida que la población va creciendo la necesidad de maquinaria se va incrementando para mantener la capacidad productiva y en las áreas más demandantes de la economía. 
Tabla 6: Población de Chile en años seleccionados y tasas de crecimiento por periodos

\begin{tabular}{|c|c|c|}
\hline Años & $\begin{array}{c}\text { Población } \\
\text { Total }\end{array}$ & $\begin{array}{c}\text { Tasa de } \\
\text { Crecimiento }\end{array}$ \\
\hline 1830 & 965.173 & $-\cdot$ \\
\hline 1850 & 1.409 .733 & 1,91 \\
\hline 1870 & 1.974 .998 & 1,7 \\
\hline 1890 & 2.607 .769 & 1,47 \\
\hline 1910 & 3.317 .166 & 1,21 \\
\hline 1938 & 4.875 .203 & 1.38 \\
\hline
\end{tabular}

Fuente: (Yáñez, Rivero, Badia-Miró, \& Carreras-Marín, 2014)

Los datos de población de Chile observados en la tabla No 6 muestran un crecimiento sostenido en el tiempo, casi quintuplicando la población inicial de 1830. ¿Cómo afectó este crecimiento la tasa de participación de la maquinaria en el producto? y por consiguiente, ¿cómo afecto el crecimiento de la población a la FBCM por habitante?

La población se quintuplicó en cien años, mientras que la $\mathrm{FBCM}$ se multiplicó por $2270^{16}$, pasando de 22.000 pesos en 1839 a 49.945.201 pesos en 1938. Esto significa que la FBCM pasó de ser de $0,02^{17}$ pesos per cápita en 1839 a 10,24 pesos per cápita en 1938 . Es un cambio sustancial, pero cuando se examina el periodo completo, se comprenden los matices. La cifra per cápita de 1938 es un tercio de la alcanzada en 1929, cuando la FBCM per cápita ascendió a 32 pesos; su descenso es dramático durante la crisis, llegando a disminuir a 1,39 pesos en 1933 , lo que equivalía a las cifras de 1870 - 1880. Hay dos periodos con cifras sobre la media; el primero, va desde 1902 hasta 1913. En este periodo, la media ponderada fue de 16,43 pesos y en el segundo, desde 1920 a 1929, la media ponderada alcanzó los 17,52 pesos per cápita.

En el gráfico No 3 es posible apreciar cómo se modifica la apreciación de la FBCM en número absolutos y en términos per cápita. Así como se moderan las alzas que se observan en los términos absolutos, es posible comprender el efecto devastador que tienen las crisis sobre la participación de la maquinaria en la población (y por ende por 
trabajador). Crisis de inversión han sido frecuentes, y la pérdida de expectativas han significado retrocesos en los procesos de acumulación de maquinaria, disminuyendo el stock por trabajador, pero en periodos posteriores a los ańos de estos pozos se producían alzas que contrarrestaban las caídas y volvían a una tendencia creciente moderada, como ocurrió con la crisis de finales de la década de 1850, la crisis de la mitad de la década de 1870 e incluso la disrupción que generó la primera Guerra Mundial. Una situación muy distinta ocurrió con la crisis de 1929, donde la inversión en maquinaria y equipos se hunde hasta 1,39 pesos de $18 \mathrm{~d}$ per cápita en 1933, y no se recuperó a los niveles de 1929 en lo que respecta al periodo estudiado en este trabajo. En pocas palabras, la inversión per cápita en maquinaria por habitante de 1938 es similar a la inversión per cápita por habitante de 1905, situación que se traducirá en un bajo nivel de stock de capital por trabajador (Tafunell \& Ducoing, 2015). Estas magnitudes nos ponen en evidencia las características económicas de Chile en los inicios de la ISI; el país sufría una carencia de inversión por habitante manifiesta, y aunque el censo industrial de 1937 muestre un aumento de los índices por habitante, estos números responden más a una reacción tardía y recuperación de los valores previos a la crisis.

Gráfico 3: Inversión en maquinaria y equipos per cápita 1839 - 1938. Pesos de $18 \mathrm{~d}$.

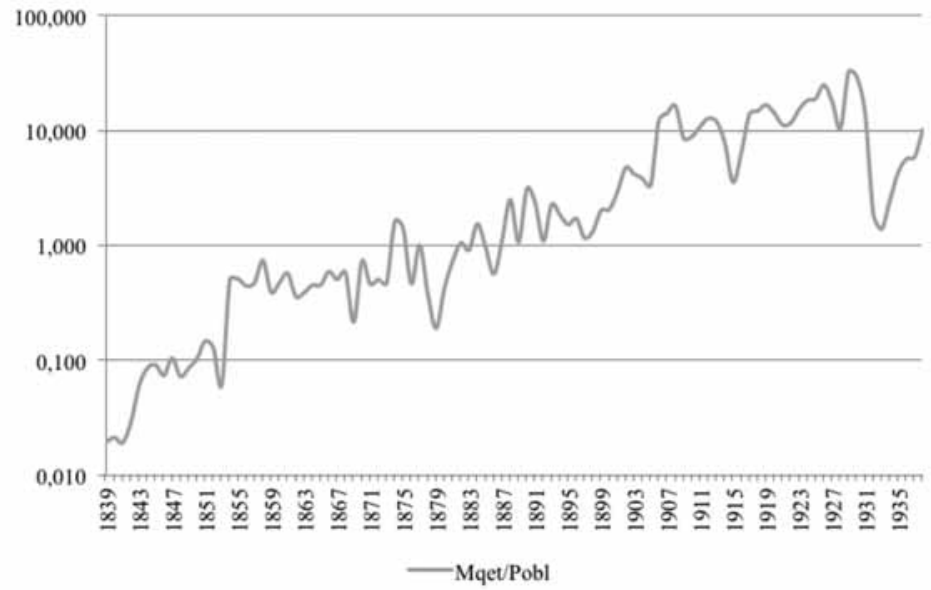

Fuente: FBCM (Ducoing, 2012) y población (Yáñez et al., 2014) 


\section{PARTICIPACIÓN SECTORIAL DE LA FBCM}

Una serie de alcances se deben hacer antes de presentar los resultados sectoriales de la FBCM. En primer lugar, pese a que la presentación de esta sección contiene los sectores agregados más utilizados en los estudios sectoriales, referidos a; Industria, Agricultura, Minería, Transporte y Servicios, hay un quinto grupo, que en la estadística comercial es llamado la mayoría del tiempo "Artes y Ciencias", en el trabajo actual se considera "Servicios y Ciencias". Se han eliminado los instrumentos musicales de las estadísticas de Artes y Ciencias; si hubieran sido un elemento marginal en la contabilidad de la FBCM, probablemente no hubiera sido necesario depurar, pero en los ańos comprendidos en la década de 1850 y 1860, llegaban a representar una sobrestimación cercana al 10\% del total de la maquinaria.

No parece haber discusión en la historiografía económica chilena sobre los distintos productos que conformaron la fisonomía del país en el periodo 1830 - 1938 (Carmagnani, 1998; Meller, 1996; Ortega, 2005; J. G. Palma, 1979; Salazar, 2009). El trigo, el cobre y el salitre fueron los principales productos de exportación y son los que entregaron la mayor parte de los recursos fiscales y las divisas para promover la modernización ${ }^{18}$. No obstante, queda la duda sobre el nivel de importancia y las cronologías propias de estos productos. Por lo demás, si existe un discurso sobre una probable industrialización temprana, esta industria debería estar representada en mayores importaciones de maquinaria para la producción de bienes en el periodo que se defiende la instalación de una industria en el país, 1850 - 1880 para Ortega (2005), 1880 - 1900 para Salazar (2009) y 1880 - 1920 para G. Palma (2000) y J. G. Palma (1979). A continuación, se presenta un análisis detallado de cada sector productivo, con el fin de conocer sus dinámicas de crecimiento y estancamiento, que permiten revelar los procesos de cambio estructural y coyuntural de la economía chilena.

\section{INDUSTRIA}

El caso siempre emblemático de la industria, ha generado una serie de estudios sobre su nivel, características e importancia dentro de la economía nacional. La fundación de la SOFOFA ${ }^{19}$ en 1883 inició 
un periodo de profunda reflexión sobre el papel y la promoción de la industria en Chile ${ }^{20}$. El auge salitrero y la consecuente bonanza "fácil" que generó el llamado "oro blanco", desvió la atención sobre la industria, y las políticas proteccionistas y/o industrialista no fueron una prioridad durante los años 1880 - 1929. La Gran Depresión y sus devastadores efectos sobre el crecimiento, significaron el surgimiento de una mirada muy escéptica sobre el desarrollo económico basado en el comercio exterior y las exportaciones de recursos naturales, estableciendo al Estado como motor del crecimiento. Esto no significó que el cobre, por ejemplo, dejara de ser base fundamental de la economía chilena en el periodo posterior al que examina este artículo (1939 1973), pero si impulsó una profunda reestructuración del papel del Estado en la economía ${ }^{21}$.

Ha habido una serie de intentos por medir el nivel del output industrial (y de esta forma la industrialización temprana) de Chile en el periodo previo a la ISI y la Primera Guerra Mundial (1870 - 1880). Una serie de trabajos que podrían ser considerados descriptivos, como el realizado por Ortega Martínez \& Pinto Vallejos (1990), por medio del estudio de ciertas casos manufactureros establecen una "industrialización” previa al periodo salitrero, culpando a las instituciones del fracaso industrial en lo referido a la carencia de una política estatal. Los trabajos cuantitativos comienzan a ser elaborados en la década de los 60 y tienen como característica el intento de estimar el alcance y magnitud de la industria en Chile antes de la ISI. Uno de los más connotados fue el realizado por el investigador norteamericano Kirsch (1977), quien utilizando las series de output industrial construidas por Muñoz Gomá (1968) y una regresión de dos variables, realizó una estimación del producto industrial entre 1880 - 1915.

La serie de producto industrial para el periodo 1880 - 1938 fue recientemente actualizada en el trabajo del proxy de industrialización, obtenido por medio de la formación bruta de capital en maquinaria para la industria (desde ahora, FBCMI), el cual es medido como participación en las importaciones de maquinaria, la participación de la FBCMI en las importaciones totales y la participación de la FBCMI en el PIB. Los resultados descriptivos, por periodos, están sintetizados en la tabla No 7 . 
Tabla 7: Participación sectorial de la maquinaria industrial en las importaciones de maquinaria, las importaciones y el PIB, periodos seleccionados

\begin{tabular}{|c|c|c|c|c|}
\hline & $1830-1850$ & $1851-1879$ & $1880-1913$ & $1914-1938$ \\
\hline FBCMI/Imp.mch & $46,30 \% *$ & $32,70 \% *$ & $30,99 \%$ & $24,97^{*} *$ \\
\hline FBCMI/Imp & $0,55 \%$ & $1,34 \%$ & $4,35 \%$ & $4.67 \%$ \\
\hline FBCMI/PIB & - & $0,13 \%$ & $0.97 \%$ & $0.97 \%$ \\
\hline
\end{tabular}

Fuente: Datos de Importaciones, Anuarios Estadísticos, varios años. *Considera Herramientas para artesanos.

**La cifra puede ser artificialmente menor a la real, porque maquinaria eléctrica y, motores y calderas, comienza a ser contabilizado desde 1911 en forma separada de su sector de destino.

Chile no ha sido industrializado, en ningún momento de su historia ${ }^{22}$. Si entendemos como país industrializado a un país que el $35 \%$ de su output proviene de los productos manufacturados, Chile no ha sido industrializado; si entendemos como industrializado a un país donde el 35\% de su población está empleada en el sector secundario, Chile no ha sido industrializado; si entendemos como país industrializado a un territorio donde la mayoría de las actividades económicas tienen relación con la producción de manufacturas, Chile no ha sido industrializado ${ }^{23}$. Por lo tanto, ¿qué provoca que la mayoría de los estudios sobre el desarrollo económico de Chile fijen su atención en la industrialización? Creemos, que existe una sobrevaloración de este proceso y podemos afirmar que las cifras demuestran que Chile estuvo lejos de industrializarse y como resultado alcanzar el desarrollo. Es cierto que el país estuvo a la par en PIB per cápita durante el siglo XIX con países como Finlandia, Suecia y Portugal, países que en diferentes periodos del siglo XX cruzaron el umbral del subdesarrollo, pero en estas comparaciones se olvida que estos países eran subdesarrollados en los periodos que se compara con Chile. Pese a que los resultados de los años previos al ciclo salitrero no son despreciables, es importante recalcar que la medición en los primeros años de este trabajo incluye la participación de las herramientas para artesanos, que durante los años 1840 - $1860 \mathrm{al}-$ 
canzaron cifras importantes, como en 1853 y 1854 , con el $68,68 \%$ y el $51,85 \%$ del total de la maquinaria industrial respectivamente ${ }^{24}$. Estos datos deben reafirmar la idea de la modernización de Chile, pero es difícil sustentar la posibilidad de un desarrollo industrial si la mayoría de la FBCM está formada por útiles y herramientas. Hubo focos de crecimiento industrial en Chile, antes de la ISI y es indudable, y más aún en el periodo 1895 - 1912, donde el porcentaje de la maquinaria industrial sobre el total de la FBCM alcanzó cifras promedio de 38,58\%, junto con ańos extraordinarios, como 1903, donde está cifra se elevó hasta el 53,70\%. En el último periodo estudiado en este trabajo, las cifras de participación de la maquinaria industrial sobre el total de la FBCM comienzan a disminuir, y el promedio de 1913 - 1938, periodo que cubre la Primera Guerra Mundial (1914 - 1918) y la gran depresión de 1929 - 1932, alcanzó una cifra de 25,14\%, aunque ciertos elementos que antes se contabilizaban como maquinaria industrial dejaron de serlo, como motores y calderas ${ }^{25}$; aunque se agreguen estos elementos a la contabilidad de la maquinaria industrial esta participación sigue siendo menor que en el periodo precedente, por lo tanto, es posible afirmar que el impulso industrial se había ralentizado hacia 1938 y que las razones que esgrimieron los impulsores de la ISI estaban sustentadas por la carencia de un sector manufacturero lo suficientemente dinámico para llevar a cabo una transformación productiva y a la vez, disminuir la dependencia del país en la explotación de sus recursos naturales. Las cifras previas a 1938, especialmente desde 1933 hasta el año final de este estudio, muestran un leve repunte en la maquinaria destinada a la producción industrial, aunque este cambio en los porcentajes puede responder también a una debilidad de los otros sectores, especialmente con la disminución significativa de las inversiones en ferrocarriles.

\section{Agricultura}

Pese al fértil valle central, la agricultura tuvo un rol menor en el esfuerzo inversor del país, cuestión que ha refrendado la historiografía económica chilena, principalmente porque existe una noción nega- 
tiva $^{26}$ con respecto al ciclo que debió haber impulsado la mecanización de la agricultura, referido al crecimiento de la actividad triguera producto del shock de demanda que inició la conquista del oeste estadounidense en la llamada gold rush junto con la colonización australiana. Esta coyuntura favorable habría otorgado los incentivos precisos para generar un acelerado proceso de crecimiento en las inversiones de molinos, segadoras e instrumentos y herramientas varios para la actividad agrícola, pero el fin abrupto de los incentivos por parte del exterior terminó con este ciclo virtuoso. Las cifras correspondientes a la formación bruta de capital fijo en maquinaria para la agricultura, otorgan una impresión similar. Por un lado, disminuye la participación de la maquinaria agrícola y a la vez se reducen las tasas de la FBCM en el producto. En el caso específico del ciclo triguero, considerando el periodo $1851-1858$, la tasa de participación de la maquinaria alcanzó en promedio el 16,43\% del total de la FBCM. En los años siguientes, 1859 - 1866, esta cifra se redujo al $3,71 \%{ }^{27}$.

Se han elaborado estudios específicos sobre la modernización de la agricultura, como el trabajo de Robles (2003) donde se expone la transición hacia el capitalismo de la sociedad agraria chilena. No obstante, esta transición hacia una agricultura avanzada y mecanizada no se vio reflejada en un avance de la inversión de maquinaria agrícola en participación con el total de la FBCM en el largo plazo. Durante el periodo que cubre los inicios del país independiente hasta la crisis de mediados de la década de 1870, la adquisición de máquinas y útiles para la agricultura alcanzó un promedio de $11,79 \%$ sobre el total de la FBCM, destacando la adquisición de molinos y arados. Más destacable aún, es que en una serie de años, la importación de maquinaria destinada a la agricultura superara a la inversión de maquinaria destinada a la industria y el transporte.

La impresión resultante de las cifras de inversión en maquinaria destinada a la agricultura en el largo plazo lleva a dos hipótesis. 1) Los incentivos para la inversión de la maquinaria agrícola fueron menores a los otros sectores de la economía; 2) Las inversio- 
nes iniciales en molinos, segadoras respondía a ciclos específicos y aumentando la capacidad potencial de la economía agrícola, reducían la necesidad de nuevas inversiones hasta un nuevo ciclo. Ambas hipótesis pueden estar en lo correcto, puesto que la agricultura contaba con una masa laboral mayor al resto de los sectores productivos, siendo la población chilena eminentemente rural hasta inicios del siglo XX y, con respecto a la hipótesis 2, es posible adelantar que pese a la baja sustancial de la inversión en maquinaria agrícola al terminar el ciclo favorable de la coyuntura agrícola de los mercados de California y Australia, se haya generado un stock de capital en maquinaria agrícola lo suficientemente abultado para mantener tasas de crecimiento positivas por parte de las exportaciones agrícolas.

Como consecuencia del cambio estructural que sufrió la economía chilena luego de la Guerra del Pacífico, desde una sociedad agrícola - minera, dispersa espacialmente, hacia la confección de una sociedad urbana, con emprendimientos industriales y una importante actividad minera radicada en el salitre, la tasa de participación de la agricultura comenzó un retroceso frente a la actividades mineras e industriales, junto con una mayor inversión en los transportes (Badia-Miró, 2015). Esta situación se revierte desde la Primera Guerra Mundial, cuando el mercado interno producido por los cambios económicos del salitre se consolidó y exigió una mayor cantidad de productos agrícolas para abastecer los mercados mineros y urbanos ${ }^{28}$.

Tabla 8: Participación sectorial de la maquinaria Agrícola en las importaciones de maquinaria, las importaciones y el PIB, periodos seleccionados

\begin{tabular}{|c|c|c|c|c|}
\hline & $\mathbf{1 8 3 0 - 1 8 5 0}$ & $\mathbf{1 8 5 1 - 1 8 7 9}$ & $\mathbf{1 8 8 0 - 1 9 1 3}$ & $\mathbf{1 9 1 4}-\mathbf{1 9 3 8}$ \\
\hline FBCMAg/Imp.mch & $10,76 \%$ & $11,56 \%$ & $8,44 \%$ & $11,19 \%$ \\
\hline FBCMAg/Imp & $0,13 \%$ & $0,47 \%$ & $1,10 \%$ & $2,09 \%$ \\
\hline FBCMAg/PIB & $0,01 \%$ & $0,05 \%$ & $0,24 \%$ & $0,43 \%$ \\
\hline
\end{tabular}

Fuente: (Ducoing, 2012) 
Un último punto para poner en perspectiva la tasa de participación de la maquinaria agrícola en el total de la FBCM; los datos muestran una presencia constante de la agricultura en la FBCM, cercana al 10\%, que no se puede considerar menor. Pero hay que establecer un alcance, pues así como la tasa de participación de la maquinaria agrícola en el total de la FBCM se mantuvo estable, también lo hizo la participación de la fuerza laboral agrícola en el total de la fuerza laboral. En 1880, la participación de los trabajadores agrícolas alcanzaba el $43,7 \%$ del total; esta cifra se había reducido levemente, alcanzando el $38,9 \%$ en $1930^{29}$. Por lo tanto, la dinámica de la inversión en maquinaria agrícola tiene profunda relación con el relativo estancamiento del sector agrícola en relación a los otros sectores de la economía chilena y no una dinámica particular de la FBCM en agricultura con respecto a los otros sectores de la maquinaria.

\section{MineRÍA}

Todo análisis económico sobre Chile debe tener en cuenta la minería. Desde la época prehispánica, el destino de los habitantes del territorio chileno actual ha estado ligado a la extracción de los recursos minerales, y el periodo 1830 - 1938 no es la excepción. Los cambios tecnológicos que ocurrieron durante el siglo XIX, aumentaron la capacidad productiva de los yacimientos mineros y pudieron convertir a Chile en un importante productor mundial de plata y cobre. El análisis de la participación sectorial de la minería en la inversión en maquinaria arroja muchas luces sobre los periodos, importancia, surgimiento y desarrollo de la industria minera en Chile.

La historia económica de la adquisición de bienes de equipo destinados a la minería está configurada por los distintos ciclos de los recursos minerales, los cuales estuvieron presentes a lo largo de los 108 años que cubre este estudio. El primer ciclo, que perduró por más tiempo, es el mineral que requiere de mayor cantidad de bienes de equipo para su extracción y fundición; el cobre. Por sus características físicas, el cobre es un producto metálico con encadenamientos ligados a la inversión en maquinaria avanzada, ya que la expor- 
tación de cobre es en su inmensa mayoría después de su fundición, especialmente en la medida que disminuye su ley. En la medida que baja la ley, tiene una rentabilidad muy baja la exportación sin procesos, por lo tanto, toda empresa de extracción de cobre trae consigo una inversión considerable en maquinarias.

Tabla 9: Participación sectorial de la maquinaria para la minería en las importaciones de maquinaria, las importaciones y el PIB, periodos seleccionados

\begin{tabular}{|c|c|c|c|c|}
\hline & $\mathbf{1 8 3 0} \mathbf{- 1 8 5 0}$ & $\mathbf{1 8 5 1 - 1 8 7 9}$ & $\mathbf{1 8 8 0 - 1 9 1 3}$ & $\mathbf{1 9 1 4}-\mathbf{1 9 3 8}$ \\
\hline FBCMMi/Imp.mch & $4,38 \%$ & $2,71 \%$ & $12,62 \%$ & $11,19 \%$ \\
\hline FBCMMi/Imp & $0,05 \%$ & $0,11 \%$ & $1,64 \%$ & $2,09 \%$ \\
\hline FBCMMi/PIB & - & $0,01 \%$ & $0,37 \%$ & $0,43 \%$ \\
\hline
\end{tabular}

Fuente: (Ducoing, 2012). *Puede existir un sesgo a la baja, producto de que las palas importadas no se especifica en la Estadística Comercial si va destinada a Minería u otro Sector, pero se sabe que la mayoría iba dirigida a las explotaciones de minerales.

El segundo ciclo de inversión minera está unido al salitre, que reemplazó al cobre en importancia luego de la Guerra del Pacífico $(1879$ - 1883). La participación de la minería en el total de la FBCM, salta de un $2,71 \%$ en el periodo 1851 - 1879, a un $12,62 \%$ en el periodo posterior, 1880 - 1913. La pregunta obvia que surge es por qué razón, si el cobre necesita mayor cantidad de maquinaria que el salitre, el periodo marcado por la explotación salitrera acapara una mayor cantidad de inversión. Esta pregunta se responde de dos formas. La primera, es entender que el mercado de cobre aunque necesita de mayor cantidad de maquinarias, puesto que requiere fundición a altas temperaturas, en el periodo 1830 - 1938 su explotación estuvo ligada a yacimientos de alta ley. Por tanto, la necesidad de grandes hornos de fundición es menor, pese a la leyenda del mineral y fundición de Tamaya, propiedad de José Tomás Urmeneta ${ }^{30}$. La segunda forma para responder esta razonable conjetura es la dimensión de la industria del salitre; pese a que Chile fue perdiendo peso en la industria global de nitratos con el paso del tiempo, la dimensión que alcanzó la explotación salitrera fue de mucha mayor importancia, alcance y magnitud que la explotación 
cuprífera del siglo XIX. Algunas teorías relacionan la caída de la participación en el mercado cuprífero con los altos impuestos aplicados a su extracción - exportación, aunque es probable que la caída de la participación esté relacionada con las inversiones moderadas en innovaciones tecnológicas.

¿Es concordante la tasa de participación de la maquinaria para la minería en las importaciones de maquinaria, las importaciones totales y el producto? Es complicado determinar cuál es la tasa óptima de inversión en determinado sector, pero es evidente que la pérdida de posicionamiento internacional en los dos productos principales que poseía Chile, el salitre y el cobre ${ }^{31}$, tiene relación con un retraso tecnológico; en la década de 1870 cayó la importación de maquinaria destinada al beneficio de minerales y las fundiciones. En el mismo sentido, luego de importantes inversiones en maquinaria para beneficiar al salitre durante la década de 1880 y 1890 , se produce un descenso de estas importaciones y un aumento de las importaciones destinadas a la minería, pero de menor valor tecnológico, como son los útiles y herramientas de la minería. Por lo tanto, aunque la tasa global de inversión en maquinaria para la minería aumentó su participación en el total de la FBCM, estas no están relacionadas con los puntales de la innovación tecnológica y la preponderancia de la industria salitrera, menos demandante de maquinarias complejas que la industria cuprífera, significó un retraso cualitativo de la FBCM de la minería y en la totalidad de la inversión en maquinaria, reduciendo la capacidad de encadenamientos productivos y la posibilidad de un crecimiento sostenido de la economía chilena, más allá de sus ingenios mineros.

\section{TRANSPORTE Y EQUIPOS; ARTES Y CIENCIAS}

Esta sección cuenta con tres elementos que han variado sus clasificaciones a lo largo del periodo estudiado; el sector transporte (llamado transporte y equipos en el sistema de cuentas nacionales actual), el sector servicios (que ha variado su clasificación a lo largo de los años) y la estadística de artes y ciencias (antiguo nombre con que se clasificaban las máquinas destinadas a la música, ciencias e investigación en general). 


\section{Transporte}

Sin lugar a dudas, el ferrocarril es la base fundamental de la estadística relacionada con "transporte y equipos", principalmente porque el periodo estudiado cubre el proceso de maquinización del transporte, liderada precisamente por el ferrocarril a vapor desde su llegada a Chile en $1851^{32}$ con la inauguración del tramo Copiapó - Caldera. Incluso, en términos de construcción de maquinaria, este es el único punto en el cual Chile se puede considerar exitoso y competitivo, puesto que hasta los albores de la Primera Guerra Mundial en el país se construyeron máquinas de ferrocarril, las cuales compusieron la estructura del sistema de transporte, junto con las locomotoras y equipos importadas desde Estados Unidos e Inglaterra (Ortega, 1981; Pfeiffer, 1952).

En los años 1830 - 1850, la principal importación de equipos de transporte estaba radicada en los carruajes. Entre 1844 y 1851, el porcentaje de carruajes dentro del total de la FBCM alcanzó un promedio ponderado de $15,3 \%$, mientras que el transporte en general alcanzó el 18,8\%. Cuando surge la inversión en ferrocarriles, en 1851, el peso de los carruajes empieza a decaer rápidamente; ya en 1859 los ferrocarriles representaban 60,2\% del total de la FBCM, y los carruajes habían descendido al 6,5\% del total de la FBCM. La participación se fue moderando después de estás importantes inversiones en la década de 1850 y 1860; para 1870, el periodo de la crisis del modelo de crecimiento chileno, las cifras de inversión en transporte y ferrocarriles sufren un desplome, salvo en los años 1874 y 1875. En 1879 y 1880, en pleno conflicto bélico, la inversión en transporte como total de la FBCM cayó hasta el 9,1 y 7,0\%. Esta situación, la caída proporcional de la inversión en transportes en momentos de crisis, mayor incluso a la de la maquinaria propiamente tal, es algo que se repetirá en la historia. Por ejemplo, en 1932, punto máximo de la gran depresión en Chile, la inversión en transportes, diversificada para entonces en motores, vehículos de combustión interna, embarcaciones y ferrocarriles, cayó al 15,85\% del total de la FBCM.

Finalizada la contienda, la inversión en ferrocarriles aumentó de forma inmediata, impulsada por la necesidad de contar con medios 
de transporte para el cargamento de salitre desde las oficinas en el desierto hacia los puertos. Este "boom" en la importación de ferrocarriles y útiles comenzó a disminuir en la década de 1900 y no hubo una inversión estable en torno al 35\% del total de la FBCM desde 1909. El cambio tecnológico que supuso la introducción de los vehículos de combustión interna generó un repunte en la participación de los transportes en la FBCM y en el total de la participación de los transportes en importaciones y el PIB.

Podría darse una controversia en torno a si la inversión en maquinaria tuvo su correspondencia adecuada en los transportes, en el sentido de si la cantidad de inversiones en el transporte tuvo correlación con las necesidades de la industria minera, agrícola y manufacturera. Esto requeriría de un estudio más acabado, que no es la intención de este artículo ${ }^{33}$. Si se puede adelantar, que con tests simples, correlacionando la inversión en transportes con el precio y volumen de los principales productos de exportación de Chile durante el periodo 1844 - 1938. Observamos que la inversión en transporte responde a los incentivos que generan la posibilidad de exportar los recursos minerales y agrícolas del país. No es menor constatar que la participación en inversión transportes, casi en su mayoría, se incrementa de manera elocuente con los ciclos de la plata, cobre y el trigo en el periodo $1853-1873$ y con el boom de la exportación del salitre en el periodo posterior a la Guerra del Pacífico, 1880 - 1895.

Tabla 10: Participación sectorial de Transporte y equipos en las importaciones de maquinaria, las importaciones y el PIB, periodos seleccionados

\begin{tabular}{|c|c|c|c|c|}
\hline & $\mathbf{1 8 3 0}-\mathbf{1 8 5 0}$ & $\mathbf{1 8 5 1 - 1 8 7 9}$ & $\mathbf{1 8 8 0}-\mathbf{1 9 1 3}$ & $\mathbf{1 9 1 4}-\mathbf{1 9 3 8}$ \\
\hline FBCMMi/Imp.mch & $18,31 \%$ & $43,93 \%$ & $47,04 \%$ & $30,13 \%$ \\
\hline FBCMMi/Imp & $0,22 \%$ & $1,85 \%$ & $6,12 \%$ & $5,64 \%$ \\
\hline FBCMMi/PIB & - & $0,19 \%$ & $1,37 \%$ & $1,17 \%$ \\
\hline
\end{tabular}

Fuente: (Ducoing, 2012) Apéndice No2 
Gráfico 4: Participación sectorial de los transportes y las maquinarias en el total de la FBCM. 1844 - 1938

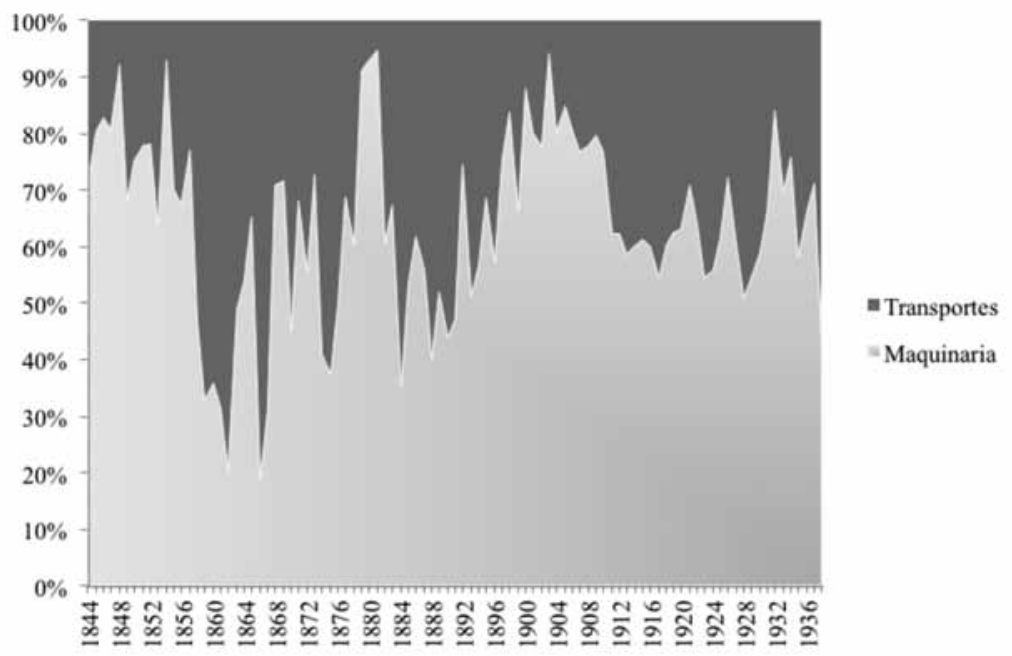

Fuente: (Ducoing, 2012)

\section{ARTES Y CIENCIAS}

Aunque actualmente no está considerada en las cuentas nacionales como un ítem de maquinaria, por más de 40 años fue considerado en las estadísticas de comercio exterior de Chile dentro del ítem de maquinaria, equipos y útiles para las industrias. Su participación en el total de las maquinarias importadas y en la FBCM ha sido sobrestimada y a la vez ha añadido valor artificialmente al total de la maquinaria en las importaciones y el producto, puesto que dentro de sus ítems estaban contabilizados los pianos, pianolas, guitarras, evidentemente, para nuestras concepciones de maquinaria, los bienes mencionados no pueden ser considerados bienes de capital, si no bienes de consumo. Otra de las dificultades para estimar este sector, es que algunas de las actividades científicas se mezclaban con las de comunicaciones, como son las importaciones de teléfonos y equipos para el telégrafo.

Durante los periodos donde su contabilidad pudo ser detectada y a la vez separada de los restantes elementos, se ha llegado 
a estimar entre 1840 - 1880 un promedio de 3,8\% de participación dentro del total de importaciones de maquinaria, siendo en su mayoría instrumentos científicos de laboratorio, elementos de ensayo, de mediciones matemáticas y maquinaria menor para elaboración de obras de arte.

\section{Conclusiones}

Los distintos estudios de casos nacionales que ha aportado la historia económica, muestran que son muy pocos los casos de éxito de los países "periféricos" en el periodo 1870 - 1930. No obstante, diversas regiones con prometedores resultados durante la primera globalización defraudaron las expectativas y se quedaron rezagadas en el camino del desarrollo.

El caso de Chile y su formación bruta de capital en maquinaria y sus variables asociadas ha permitido analizar profundamente la dinámica de crecimiento del país en un periodo clave de su desarrollo. En 1830, una nueva nación independiente se convirtió en un importante exportador de nitratos a finales del siglo XIX. En 1938, este país decidió tomar un camino a través del desarrollo hacia adentro para hacer frente a los fracasos de los modelos de crecimiento relacionados con el sector externo. Si este era el camino correcto, a este trabajo no le corresponde presentar respuestas en ese sentido, pero se puede aventurar que muchas de las dificultades que enfrentó el país en el modelo de desarrollo industrial para el período desde 1939 a 1973 tienen su origen en la debilidad estructural 18301938, especialmente en la pérdida de dinamismo de la inversión de los principales sectores en los años posteriores a la Primera Guerra Mundial y durante la Gran Depresión, desde 1929 hasta 1932, que en el caso de Chile, pese a su reconocida pronta recuperación, no logró retomar los niveles de inversión de los años 1927 -1929 hasta bien entrada la década de 1940 . 
Bibliografía

ALLEN, R. C. (2009). The British industrial revolution in global perspective. Cambridge: Cambridge University Press.

ALLEN, R. C. (2014). American Exceptionalism as a Problem in Global History. The Journal of Economic History, 74(02), 309350. http://doi.org/10.1017/S002205071400028X

BADIA MIRÓ, M. (2011). La localización de la actividad económica en Chile, 1890-1973. Su impacto de largo plazo. Retrieved from http://www.tdx.cat/handle/10803/2060

BADIA-MIRÓ, M. (2015). The evolution of the location of economic activity in Chile in the long run: a paradox of extreme concentration in absence of agglomeration economies. Estudios de Economia, 42(2), 143-167. http://doi.org/10.4067/S071852862015000200007

BADIA-MIRÓ, M., \& DUCOING, C. (2013). El PIB industrial de Chile durante el ciclo del salitre, 1880 - 1930. Revista Uruguaya de Historia Económica, III(3), 11-32. Retrieved from http://www.audhe.org.uy/ano-3-numero-3.html

BADIA-MIRÓ, M., \& DUCOING, C. (2015). The long run development of Chile and the Natural Resources curse. Linkages, policy and growth, 1850-1950. In M. Badia-Miró, V. Pinilla, \& H. Willebald (Eds.), Natural Resources and Economic Growth. Lessons from History. Routledge.

BÉRTOLA, L., \& OCAMPO, J. A. (2013). El desarrollo económico de América Latina desde la Independencia (Google eBook). Fondo de Cultura Economica. Retrieved from http://books. google.com/books?id=T2W2AwAAQBAJ\&pgis=1

BOLT, J., \& VAN ZANDEN, J. L. (2014). The Maddison Project: collaborative research on historical national accounts. The Economic History Review, n/a-n/a. http://doi.org/10.1111/14680289.12032

CARIOLA, C., \& SUNKEL, O. (1982). Un siglo de historia económica de Chile 1830 - 1930. Dos ensayos y una bibliografía. Madrid: Cultura Hispánica. 
CARMAGNANI, M. (1998). Desarrollo industrial y subdesarrollo económico: El caso chileno (1860-1920) (Vol. 16). Santiago de Chile, Chile: Ediciones de la Direcci6n de Bibliotecas, Archivos y Museos. CARMAGNANI, M. (2001). Los Mecanismos de la vida económica en una sociedad colonial: Chile 16801830. Retrieved from http://books.google.es/books/ about/Los_Mecanismos_de_la_vida_económica_ en.html? id=vwpkAAAAMAAJ \&pgis=1

CHOW, G. C. (1960). Tests of Equality Between Sets of Coefficients in Two Linear Regressions. Econometrica, 28(3), pp. 591-605. Retrieved from http://www.jstor.org/stable/1910133

CULVER, W. W., \& REINHART, C. J. (1989). Capitalist Dreams: Chile's Response to Nineteenth-Century World Copper Competition. Comparative Studies in Society and History, 31(4), 722-744. Retrieved from http://www.jstor.org/ stable/ 179076

DELONG, B., \& SUMMERS, L. (1991). Equipment Investment and Economic Growth. Quarterly Journal of Economics. Retrieved from http://ecsocman.hse.ru/rubezh/ msg/18727031.html

DELONG, J. B. (1992). Productivity Growth and Machinery Investment: A Long-Run Look, 1870-1980. The Journal of Economic History, 52(02), 307-324. http://doi.org/10.1017/ S0022050700010755

DELONG, J. B., \& SUMMERS, L. H. (1991). Equipment Investment and Economic Growth. The Quarterly Journal of Economics, 106(2), 445-502. http://doi. org/10.2307/2937944

DELONG, J. B., \& SUMMERS, L. H. (1992). Equipment Investment and Economic Growth: How Strong Is the Nexus? Brookings Papers on Economic Activity, 23(2), 157-212. Retrieved from http://econpapers.repec.org/RePEc:bin:bpeajo:v:23:y:19 92:i:1992-2:p:157-212

DÍAZ, J., LÜDERS, R., \& WAGNER, G. (2010). La República en Cifras, 2010. Retrieved from http://www.economia.puc.cl/cliolab 
DUCOING, C. (2012). Inversión en maquinaria, productividad del capital y crecimiento económico en el largo plazo. Chile 1830 - 1938, Tesis de doctor en Historia Económica, Universitat de Barcelona (Inédita).

DUCOING, C., \& TAFUNELL, X. (2013). Formación bruta de capital en bienes de equipo en Chile, 1856-1930. Fuentes nacionales y extranjeras [Gross Capital Formation in Equipment in Chile, 1856-1930. National and Foreign Sources]. América Latina En La Historia Económica, 20(1), 5-34.

FFRENC-DAVIS, R., MUÑOZ, Ó., BENAVENTE, J. M., \& CRESPI, G. (2000). The Industrialization of Chile during Protectionism, 1940 - 82. In E. Cardenas, J. A. Ocampo, \& R. Thorp (Eds.), An Economic History of Twentieth-Century Latin America (Vol. 3, pp. 114-153). Palgrave, New York.

GREENWOOD, J., HERCOWITZ, Z., \& KRUSELL, P. (1997). Long-Run Implications of Investment-Specific Technological Change. The American Economic Review, 87(3), pp. 342-362. Retrieved from http://www.jstor.org/stable/2951349

KIRSCH, H. W. (1977). Industrial development in a traditional society : the conflict of entrepreneurship and modernization in Chile. Gainesville Fla.: University of Florida Press.

LOBELL, H., SCHÖN, L., \& KRANTZ, O. (2008). Swedish Historical National Accounts, 1800-2000: Principles and Implications of a New Generation. Scandinavian Economic History Review. Retrieved from http://www.tandfonline.com/doi/ full/10.1080/03585520802191282

LÜDERS, R. J., \& WAGNER, G. (2003). Export Tariff, Welfare and Public Finance: Nitrates from 1880 to 1930. Documentos de Trabajo - PUC, 241.

MAGENDZO, I. (2004). Determinantes de la Inversión en Chile. Working Papers Central Bank of Chile. Central Bank of Chile. Retrieved from http://ideas.repec.org/p/chb/bcchwp/303.html MAMALAKIS, M. J. (1976). The Growth and structure of the chilean economy :from independence to Allende. New Haven: Yale University Press. 
MATUS, M. (Ed.). (2009). Hombres del metal: trabajadores ferroviarios y metalúrgicos chilenos en el Ciclo Salitrero, 18801930. Retrieved from http://books.google.cl/books/about/ Hombres_del_metal.html?hl=es\&id=MxORZwEACAAJ\& pgis $=1$

MELLER, P. (1996). Un Siglo de economía política chilena (1890-1990). Retrieved from http://books.google.es/ books/about/Un_Siglo_de_economía_política_chilena. html?id=IUy5AAAAIAAJ\&pgis=1

MUÑOZ GOMÁ, Ó. (1968). Crecimiento Industrial de Chile: 1914 - 1965. Santiago: Instituto de Economía y Planificación. ORTEGA, L. \& PINTO, J. (1990). Expansión minera y desarrollo industrial: un caso de crecimiento asociado (Chile 1850-1914) Expansión minera y desarrollo industrial: un caso de crecimiento asociado (Chile 1850-1914). Santiago de Chile, Chile: U. de Santiago, Depto. de Historia.

ORTEGA, L. (1981). Acerca de los orígenes de la industrialización chilena (1860 - 1879). Nueva Historia, 1(2), Londres.

ORTEGA, L. (2005). Chile en Ruta Al Capitalismo: Cambio, Euforia y Depresión 1850-1880. Santiago de Chile, Chile: Lom.

PALMA, G. (2000). Trying to "tax and spend" oneself out of the "Dutch Disease": The Chilean Economy from the War of the Pacific to the Great Depression. In An Economic History of Twentieth-Century Latin America, Volume 1: The Export Age: The Latin American Economies in the Late Nineteenth and Early Twentieth Centuries (Vol. 1). Palgrave MacMillan. Retrieved from http://books.google.es/books?id=B4-mjwEACAAJ

PALMA, J. G. (1979). Growth and structure of Chilean manufacturing industry from 1830 to 1935. University of Oxford.

PFEIFFER, J. (1952). Notes on the Heavy Equipment Industry in Chile, 1800-1910. The Hispanic American Historical Review. Retrieved from http://www.jstor.org/stable/2508942

PRADOS DE LA ESCOSURA, L. (2003). El Progreso económico de España 1850-2000. Bilbao: Fundación BBVA. 
ROBLES, C. (2003). Expansión y transformación de la agricultura en una economía exportadora: la transición al capitalismo en Chile (1850-1930). Historia Agraria: Revista de Agricultura E Historia Rural. Retrieved from http://dialnet.unirioja.es/descarga/articulo/643211.pdf

ROMER, P. M. (1986). Increasing Returns and Long-Run Growth. Journal of Political Economy, 94(5), pp. 1002-1037. Retrieved from http://www.jstor.org/stable/1833190

SALAZAR, G. (2009). Mercaderes, Empresarios y Capitalistas: Chile, Siglo XIX. Editorial Sudamericana. Retrieved from http://books.google.es/books?id=owldQwAACAAJ

SOLOW, R. M. (1956). A Contribution to the Theory of Economic Growth. The Quarterly Journal of Economics, 70(1), pp. 65-94. Retrieved from http://www.jstor.org/stable/1884513

TAFUNELL, X. (2009). Capital Formation in Machinery in Latin America, 1890-1930. The Journal of Economic History, 69(04), 928. Retrieved from http://dx.doi.org/10.1017/ S0022050709001338

TAFUNELL, X. (2013). Capital formation in Latin America: one and a half century of macroeconomic dynamics. CEPAL Review, 109, 7-28.

TAFUNELL, X., \& DUCOING, C. (2015). Non-Residential Capital Stock in Latin America, 1875-2008: New Estimates and International Comparisons. Australian Economic History Review, n/a-n/a. http://doi.org/10.1111/ aehr. 12076

VALENZUELA, L. (1995). Tres estudios sobre el comercio y la fundición de cobre en Chile y en el mercado mundial, 1830-1880. Santiago: Librería Chile Ilustrado.

YÁÑEZ, C., RIVERO, R., BADIA-MIRÓ, M., \& CARRERAS-MARÍN, A. (2014). Nuevas series anuales de población de América Latina desde el siglo XIX hasta el 2000. Scripta Nova. Revista .... Retrieved from http://diposit.ub.edu/dspace/handle/2445/5634 


\section{FUENTES}

Las fuentes mencionadas en esta sección han sido utilizadas en la construcción de la serie elaborada en (Ducoing, 2012) y la división sectorial presentada en este artículo.

Fuentes Chilenas, Publicaciones Periódicas

Estadística Comercial de Chile, varios años 1844- 1909.

Anuario Estadistico de la República de Chile. Varios Años, 1910 1930. 1893, 1894, 1896, 1898, 1900, 1901, 1909, 1910 - 1916, 1919 - 1924, 1927, 1929, 1931 - 1938.

Anuario de Comercio Internacional de Chile: 1902 - 1908, 1917, 1918, 1925 - 1928.

Oficina de Estadísticas. Sinopsis Geográfica y Estadistica de la República de Chile. Varios Años 1918 - 1925.

\section{Publicaciones Oficiales}

Superintendencia de Aduanas. Departamento de Estadística Comercial. "Resumen del Comercio Exterior de Chile en el año de 1907. Importación y Exportación" Sociedad Imprenta y Litografía Universo. 1908.

Alberto Herrmann. Observaciones a la Estadistica del Comercio Esterior de Chile (1889 - 1890). Calculado al cambio de 38 peniques por peso. Sociedad Nacional de Minería. Imprenta Nacional Moneda, Santiago de Chile, 1892.

República de Chile. Memoria del Superintendente de Aduanas sobre la renta y el comercio exterior en 1901. Imprenta del Universo de Guillermo Helfmann, Valparaíso, 1902.

Mensaje leido por S.E. el Presidente de la República en la apertura de las Sesiones Ordinarias del Congreso Nacional. Santiago de Chile, Imprenta Nacional. 1915.

Aprovisionamientos del estado. República de Chile / Ministerio de Relaciones Exteriores de Chile. Imprenta Universo. 1929. 


\section{Fuentes Extranjeras}

\section{EsTADOS UNIDOS}

Estados Unidos. U.S. Department of Commerce. Bureau of Statistics, The Foreign Commerce and Navigation of the United States, Washington, varios años.

Estados Unidos. U.S. Treasury Department. Bureau of Statistics, The Foreign Commerce and Navigation of the United States (el título va variando ligeramente), Washington, varios años.

Estados Unidos. U.S. Department of Commerce, Commerce Yearbook 1926, 2 vols., Washington, 1928.

Estados Unidos. U.S Bureau of Foreign Commerce United States consular reports. Varios Años, 1890 - 1910. Ubicación, British Library.

\section{REINO UNIDO}

Reino Unido. Statistical Office of the Customs and Excise Department, Annual Statement of the Trade of the United Kingdom with Foreign Countries and Britain possessions, Londres, varios ańos.

\section{Notas de PÁgina}

'El trabajo de (Solow, 1956), que dio origen al llamado modelo Solow - Swan, es considerado el iniciador de la teoría moderna del crecimiento económico. El modelo, aunque simple, explica de manera detallada el crecimiento económico de los Estados Unidos, y se basa en que la acumulación de capital no sostiene de por si el crecimiento económico, y que es el progreso técnico el capaz de otorgar saltos de productividad y otorgar crecimiento sostenido a las economías. Como el avance técnico se estimaba externo al crecimiento de la economía, esta teoría comúnmente se llama “exógena”. Un punto importante y necesario de aclarar, es que este modelo no distingue entre stock de capital en maquinarias y estructuras. Los análisis de productividad cometen el error de valorar los stocks de capital en infraestructuras y maquinaria de la misma forma, cuando ambos poseen valoraciones muy disímiles debido a sus años de depreciación. 
${ }^{2}$ En el caso de las aportaciones de Romer, el nombre exógeno es reemplazado por endógeno, puesto que el crecimiento económico sería determinado por el cambio técnico, realizado endógenamente; (Romer, 1986).

${ }^{3}$ En directa relación con el análisis de Romer, Greenwood realiza un análisis de la importancia de la inversión en nuevos bienes de capital, que serían responsables de una parte significativa del crecimiento norteamericano de posguerra. (Greenwood et al., 1997).

${ }^{4}$ Ver (Allen, 2014). Sin embargo, sólo como medida de referencia, hemos incluido en esta introducción los datos sobre Estados Unidos.

${ }^{5}$ En algunos trabajos, se toma en cuenta un "siglo" muy similar al analizado en este artículo (Cariola \& Sunkel, 1982; Matus, 2009; J. G. Palma, 1979).

${ }^{6}$ Algunos historiadores tienden a separar los periodos económicos chilenos en antecedentes más estructurales, dejando de lados crisis y ciclos. Por ejemplo, para el historiador económico norteamericano Mamalakis, existirían dos periodos netamente diferenciados de modelos y estructuras de crecimiento; 1840 - 1930 Crecimiento exportador y 1930 - 1973 Desarrollo hacia adentro.

${ }^{7} \mathrm{La}$ opción de dejar fuera de los periodos de contracción y bonanza los años comprendidos entre 1830 - 1849, es debido a que estos años no cuentan con cifras de PIB aceptables, puesto que fueron construidas con una regresión basada principalmente en el comercio internacional. Por ejemplo, en las cifras de Díaz, entre 1830 y 1865 no existe ningún año con decrecimiento del PIB.

${ }^{8} \mathrm{La}$ determinación de un ciclo de contracción o depresión está determinado por una caída del producto consecutiva superior al $-3 \%$.

${ }^{9}$ Un quiebre estructural se define como un cambio inesperado en las series macroeconómica, cuando se refiere a series de tiempo. el tests de Chow consiste en quebrar la muestra en dos ( o más, de acuerdo al caso) estructuras, estimar la ecuación por cada una de ellas y entonces, comparar las SSR de las ecuaciones separadas con toda la muestra.

${ }^{10} \mathrm{Que}$ en diez años la inversión en maquinaria se reduzca en un $8,29 \%$ es una cifra considerable. 
${ }^{11}$ Se ha determinado dejar fuera el periodo 1830 - 1843 para no sobreestimar las tasas de crecimiento, debido al evidente efecto índice Gershenkron que provoca partir de un punto casi cero.

${ }^{12}$ Es evidente que en una situación de crisis "anormal" como la que ocurrió en 1929 las caídas de la inversión también estarán fuera de la norma o los antecedentes previos.

${ }^{13}$ En el capítulo 4 de Ducoing (2012), se analiza el Stock de capital en Maquinaria. Debido a la extraordinaria caída de la FBCM durante el periodo 1929 - 1932, se produce un efecto poco recurrente en la medición del stock, salvo cuando ocurren guerras o desastres naturales; el stock disminuirá debido a que las tasas de inversión son menores a las tasas de retiro y depreciación (Tafunell \& Ducoing, 2015)

${ }^{14} \mathrm{El}$ gráfico y este análisis no toma en cuenta el periodo de 1830 - 1859, porque los datos de PIB no son comparables por la forma de realización.

${ }^{15} \mathrm{La}$ diferencia con respecto a las importaciones se explica por dos razones principales. Por un lado, las importaciones pasaron a representar una tasa mucho menor del producto y por otra parte, existen diversos cambios en la tributación de los productos.

${ }^{16}$ Se recuerda que la importación encontrada en 1830 es de nivel tan bajo, que mensurarlo resulta desproporcionar y aumentar de forma artificial los resultados.

${ }^{17}$ En dólares corrientes, la cifra es de 0,0198 per cápita.

${ }^{18} \mathrm{La}$ discusión en torno a la modernización por medio de la acción del Estado en el siglo XIX aún está en desarrollo, puesto que no hay acuerdo en torno al carácter de las políticas públicas y si respondía a un sistema liberal, proteccionista, o simplemente pragmático.

${ }^{19}$ Sociedad de Fomento Fabril.

${ }^{20} \mathrm{En} 1877$, producto de la delicada situación fiscal del país, hubo un cambio en las tasas arancelarias para los productos importados, entre ellas las maquinarias y lo bienes de equipo. La tasa establecida fue de un 15\%, y duró hasta finales de la década de 1880. (Ortega, 2005 pp. 310) 
${ }^{21}$ Para más detalles con respecto al papel del Estado en la promoción de la industria en la economía chilena, (Ffrenc-Davis, Muñoz, Benavente, \& Crespi, 2000).

${ }^{22} \mathrm{La}$ crítica sobre la incapacidad de los sectores empresariales en Chile de destinar las inversiones a los sectores productivos se reitera, incluso, en relación a los empresarios coloniales “... si las inversiones se orientaron hacia el sector agrícola y no hacia un nuevo sector como la industria, ello al parecer no se debió esencialmente al hecho de que la industria ofrecía beneficios inferiores a los de la agricultura sino, más bien, al hecho de que las industrias por sí solas no bastaban para asegurar los beneficios." (Carmagnani, 2001) pp. 326.

${ }^{23} \mathrm{La}$ comparación con los países desarrollados de la época puede parecer forzada; pero las cifras de importación de maquinaria comparadas con cifras de (Tafunell, 2009), sitúan a Chile por detrás de Cuba y Argentina, dos países que tampoco lograron alcanzar la industrialización.

${ }^{24}$ (Ducoing, 2012) Apéndice No 2.

${ }^{25}$ Este cambio se debe a que motores y calderas no todas iban destinadas a industria y se corrigió esta situación en la estadística ubicándolas en un ítem aparte.

26"..los mercados de California y Australia no tuvieron la importancia que tradicionalmente se les ha atribuido ni como iniciadores del desarrollo agrícola chileno -que ya tenía importantes mercados en Perú- ni en cuanto a inducir su decadencia cuando se cerraron. El hecho es que las exportaciones trigueras crecieron significativamente durante dos décadas, reorientándose al mercado europeo" (Cariola \& Sunkel, 1982, pp. 35)

${ }^{27}$ Es importante recalcar que el bajo nivel de importaciones en maquinaria sobre el total de la importaciones del periodo 1830 1860, eleva artificialmente las cifras de la agricultura en el total; también se debe considerar que en los ańos 1851 y 1852 la importación de maquinaria agrícola e implementos para la agricultura no disminuyó del 30\% del total de la FBCM. En 1851 la importación de maquinaria agrícola ascendió al 33,35\% del total, $\$ 70.115$ de la época y en el año 1852, los resultados fueron el 39,28\% y $\$ 73.240$, 
respectivamente. Para 1854, la cifra de participación había disminuido, pero empujada por un alza sin precedentes de la maquinaria para la industria.

${ }^{28}$ Esta es la tesis principal defendida por (Cariola \& Sunkel, 1982, pp. $13-19$ ).

${ }^{29}$ (Braun et. al, 2000. Pp. 218 - 220, 222 - 223)

${ }^{30}$ Nazer, Ricardo. “José Tomás Urmeneta, (1808-1878) : un empresario minero del siglo XIX” en Ignacio Domeyko, José Tomás Urmeneta, Juan Brüggen : tres forjadores de la minería nacional / Julio Pinto Vallejos, Javier Jofré Rodríguez, Ricardo Nazer Ahumada. 1a. ed. [Santiago] : Instituto de Ingenieros de Minas de Chile, 1993 (Santiago : Claus von Plate) pp. 83 -154. Leyenda, en el sentido de que se ha llegado a argumentar que la magnitud de la fundación de Tamaya estaría relacionada con la quiebra de las fundiciones en Swansea, Gales.

${ }^{31}$ Los argumentos para la caída de ambos productos en la literatura están relacionados con las políticas fiscales de Chile; en el caso del cobre (Culver \& Reinhart, 1989). En el caso del salitre, existe la creencia de que Chile poseía un monopolio natural; nada más alejado de la realidad, puesto que existían varios sustitutos competidores del salitre en el mercado y para 1904 los países competidores ya estaban aumentando la producción más rápido que Chile (Lüders \& Wagner, 2003).

${ }^{32}$ Antes de esta fecha, la mayoría de la importación de medios de transporte estaba determinada por la importación de carruajes. Revisar el apéndice correspondiente al año 1854 en (Ducoing, 2012).

${ }^{33}$ Sobre la localización de la industria en Chile y la disposición de los transportes en el territorio, ver (Badia Miró, 2011; Badia-Miró, 2015)

Fecha de Recepción del Artículo: 23 de marzo de 2016 Fecha de Aprobación: 30 de mayo de 2016 